Check for updates

Cite this: RSC Adv., 2017, 7, 19486

\title{
Characterization of Dietzia cercidiphylli C-1 isolated from extra-heavy oil contaminated soil $\dagger$
}

\begin{abstract}
Xiaoli Dai, (D) Guangxu Yan and Shaohui Guo*
Bioremediation of extra-heavy oil contaminated soil has become a hot research field. It is difficult for extraheavy oil to be degraded by bacteria. In this study, strain C-1 was isolated from Venezuelan extra-heavy oilcontaminated soil. Morphological, physiological and phylogenetic analysis identified strain C-1 as Dietzia cercidiphylli. The strain could degrade $25.58 \pm 0.48 \%$ of extra-heavy oil at an initial concentration of $100 \mathrm{mg} \mathrm{L}^{-1}$ in 14 days with the degradation rate constant of 0.021 per day. GC-MS analysis demonstrated that the strain could effectively degrade medium (C13-C17) and longer (C44) length chain $n$-alkanes. This is the first report that the Dietzia strain can degrade extra-heavy oil, especially C44 $n$ alkanes. Dietzia cercidiphylli C-1 could be applied in extra-heavy oil contaminated soil bioremediation in the future.
\end{abstract}

Received 18th January 2017

Accepted 25th March 2017

DOI: $10.1039 / \mathrm{c} 7 \mathrm{ra00786h}$

rsc.li/rsc-advances

these studies focused on conventional crude oil, which is more readily degradable and easier to clean up than extra-heavy oil. There have been only a few attempts to isolate microorganisms that degrade extra-heavy oil and to use them for bioremediation of the contaminated soil environment.

It is important to obtain microorganisms that can degrade extra-heavy oil. Dietzia sp. has already been found to be capable of utilizing a wide range of $n$-alkanes. For example, Dietzia sp. A14101 depletes C6 to C26 $n$-alkanes of crude oil; ${ }^{\mathbf{1 5}}$ Dietzia sp. E1 has an excellent ability to degrade C12 to C38 $n$-alkanes, ${ }^{16}$ Dietzia sp. DQ12-45-1b grows on a wide range of $n$-alkanes (C6-C40), aromatic compounds and conventional crude oil. ${ }^{17}$ Unfortunately, it is no report that Dietzia strains can degrade extra-heavy oil.

Here, a Dietzia strain was isolated from the Venezuelan extraheavy oil contaminated soil in Liaohe oilfield (Liaoning, China), identified based on their morphological and physiological characteristics and 16S rDNA sequence analysis. As the bacterial strain showed high degradation capacity for extra-heavy oil, its degradation kinetics and degradation characteristics of extraheavy oil were analyzed. bioremediation techniques including composting, bioaugmentation and biostimulation for remediating oil contaminated soil has been reported by numerous studies. ${ }^{5-7}$ It employs microorganisms to achieve complete or partial mineralization of pollutants, resulting in their removal or transformation to a harmless product. ${ }^{5,8}$ A large number of studies showed that many kinds of microorganisms had strong ability to degrade oil. ${ }^{9-14}$ Oil-degrading microorganisms have been widely considered to be the most crucial factors governing the bioremediation of oil contaminated soil. However, most of

State Key Laboratory of Heavy Oil Processing, Beijing Key Laboratory of Oil \& Gas Pollution Control, China University of Petroleum-Beijing, 18 Fuxue Road, Changping District, Beijing 102249, PR China. E-mail: cupgsh@163.com; Tel: +8601089733335 $\uparrow$ Electronic supplementary information (ESI) available. See DOI: $10.1039 / \mathrm{c} 7 \mathrm{ra00786h}$

\section{Materials and methods}

\subsection{Sampling}

A soil sample was collected from the oil contaminated soil in Liaohe oilfield (Liaoning, China). Soil (500 g) was taken from 1 to $12 \mathrm{~cm}$ below the surface of layer using a sterile knife.

The experimental oil was Venezuelan extra-heavy crude oil with the addition of diluents. According to the analysis method mentioned in Section 2.7 , the oil contained $35.20 \%$ aliphatics, $35.18 \%$ aromatics, $19.50 \%$ asphaltenes and $10.12 \%$ resins. 


\subsection{Media}

The mineral salt medium (MSM) was composed of $\left(\mathrm{L}^{-1}\right)$ : $\left(\mathrm{NH}_{4}\right)_{2} \mathrm{SO}_{4} 5 \mathrm{~g}, \mathrm{KH}_{2} \mathrm{PO}_{4} 3.0 \mathrm{~g}, \mathrm{Na}_{2} \mathrm{HPO}_{4} \cdot 2 \mathrm{H}_{2} \mathrm{O} 2 \mathrm{~g}, \mathrm{MgSO}_{4} \cdot 7 \mathrm{H}_{2} \mathrm{O}$ $0.7 \mathrm{~g}, 1 \mathrm{~mL}$ of trace element solution and the medium $\mathrm{pH}$ was adjusted to 7.5. Solid MSM plate was prepared by adding $2.0 \mathrm{~g}$ agar into $100 \mathrm{~mL}$ MSM.

The trace element solution was composed of $\left(\mathrm{L}^{-1}\right): \mathrm{CoCl}_{2}$ $\cdot 6 \mathrm{H}_{2} \mathrm{O} 0.1 \mathrm{~g}, \mathrm{MnO}_{2} \cdot 4 \mathrm{H}_{2} \mathrm{O} 0.425 \mathrm{~g}, \mathrm{ZnCl}_{2} 0.05 \mathrm{~g}, \mathrm{NiCl}_{2} \cdot 6 \mathrm{H}_{2} \mathrm{O}$ $0.01 \mathrm{~g}, \mathrm{CuSO}_{4} \cdot 5 \mathrm{H}_{2} \mathrm{O} 0.015 \mathrm{~g}, \mathrm{Na}_{2} \mathrm{MoO}_{4} \cdot 2 \mathrm{H}_{2} \mathrm{O} 0.01 \mathrm{~g}, \mathrm{Na}_{2} \mathrm{SeO}_{4}$ $\cdot 2 \mathrm{H}_{2} \mathrm{O} 0.01 \mathrm{~g}, \mathrm{CaCl}_{2} 0.147 \mathrm{~g}$.

$\mathrm{R}_{2} \mathrm{~A}$ medium ${ }^{18}$ was composed of $\left(\mathrm{L}^{-1}\right)$ : peptone $0.5 \mathrm{~g}$, yeast extract $0.5 \mathrm{~g}$, casamino acid $0.5 \mathrm{~g}$, glucose $0.5 \mathrm{~g}$, soluble starch $0.5 \mathrm{~g}, \mathrm{~K}_{2} \mathrm{HPO}_{4} 0.3 \mathrm{~g}, \mathrm{MgSO}_{4} \cdot 7 \mathrm{H}_{2} \mathrm{O} 0.05 \mathrm{~g}$, sodium pyruvate $0.3 \mathrm{~g}$ and the medium was adjusted to 7.5. Solid $\mathrm{R}_{2} \mathrm{~A}$ medium was prepared by adding $2.0 \mathrm{~g}$ of agar into $100 \mathrm{~mL} \mathrm{R}_{2} \mathrm{~A}$.

\subsection{Isolation and screening of extra-heavy oil degrading bacteria}

Bacteria strains were isolated from the contaminated soil by cultivation in $\mathrm{R}_{2} \mathrm{~A}$ medium at $30{ }^{\circ} \mathrm{C}$ for 7 days. Selection of strains able to degrade hydrocarbons was conducted by cultivating $5 \mathrm{~mL}$ cultured aliquots on MSM ager plates with $0.1 \%(\mathrm{w} /$ v) of extra-heavy oil as the sole carbon source and energy at $30{ }^{\circ} \mathrm{C}$ for 7 days. One strain, designated strain $\mathrm{C}-1$, was selected due to its good ability in the process of extra-heavy oil degradation.

\subsection{Morphological and biochemical characteristics}

The morphological properties of strain C- 1 were examined by optical microscopy. The typical biochemical and physiological characteristics of strain C-1, including Gram staining, catalase activity, oxidase activity, Voges-Proskauer reactions, methyl red, nitrate reduction, acid from glucose, indole production, nitrate reduction and hydrogen sulfide production, were systematically analyzed according to Bergey's Manual of Determinative for Bacteriology. ${ }^{19}$

\subsection{Analysis of $16 \mathrm{~S}$ rDNA sequence and phylogenetic analysis}

Genomic DNA was extracted with D3350-01 genome DNA isolation kit (Sangon Ltd., Shanghai, China), and the extracted DNA was amplified by PCR in a peqSTAR 96 universal thermocycler (PEQLAB Biotechnology) using the genomic DNA as template and the bacterial universal primers were as follows: F27(5'-CAGCGGTACCAGAGTTTGATCCTGGCTCAG-3'); R1492(5'-CTCTCTGCAGTACGGCTACCTTGTTACGACTT- $3^{\prime}$ ). The PCR amplification was performed as follows: $94{ }^{\circ} \mathrm{C}$ for $45 \mathrm{~s}$, followed by 30 cycles of $94{ }^{\circ} \mathrm{C}$ for $45 \mathrm{~s}, 55^{\circ} \mathrm{C}$ for $30 \mathrm{~s}$ and $72{ }^{\circ} \mathrm{C}$ for $1.5 \mathrm{~min}$ and a final extension at $72{ }^{\circ} \mathrm{C}$ for $10 \mathrm{~min}$. The PCR product was sequenced by a commercial service (BGI, China). The sequences were aligned with the $16 \mathrm{~S}$ rDNA sequence of each strain by Clustal X software.

\subsection{Carbon source utilization}

Based on the result of the growth curve (Fig. S1†), the cultivation time of strain C-1 was chosen for 3 days (the logarithmic growth phase). To test the ability of strain C-1 to grow on different hydrocarbons as sole carbon sources, cells from $5 \mathrm{~mL} 3$ day-old cultured $\left(\mathrm{OD}_{600}\right.$ value of 0.9$)$ in $\mathrm{R}_{2} \mathrm{~A}$ medium were harvested by centrifugation at $5000 \mathrm{rpm}$ for $10 \mathrm{~min}$ and then washed three times with sterile saline solution to remove the residual organic compounds from the cultured solution, after which they were inoculated into $100 \mathrm{~mL}$ of MSM medium supplemented with liquid or solid hydrocarbons in $250 \mathrm{~mL}$ Erlenmeyer flasks. The final concentrations of $n$-alkanes (C6, C16, C24, C40), cyclohexane (C6) and aromatic naphthalin, phenanthrene, fluoranthene, anthracene, pyrene, benzene and ethanol in the flasks were $0.3 \%(\mathrm{v} / \mathrm{v})$ for liquid alkanes, $0.05 \%(\mathrm{w} / \mathrm{v})$ for solid alkanes and aromatic hydrocarbons. Two controls, one containing cells and no hydrocarbons and another containing hydrocarbons and no cells, were used. All cultures were incubated in the dark at $30{ }^{\circ} \mathrm{C}$ for 7 days while shaking at $180 \mathrm{rpm}$, then cell growth was recorded by measuring $\mathrm{OD}_{600}$ in the medium.

\subsection{Degradation of extra-heavy oil by strain C-1}

After growth in $\mathrm{R}_{2} \mathrm{~A}$ liquid medium at $30{ }^{\circ} \mathrm{C}$ for 3 days, cells in 5 $\mathrm{mL}$ broth $\left(\mathrm{OD}_{600}\right.$ value of 0.9$)$ were harvested by centrifugation at $5000 \mathrm{rpm}$ for $10 \mathrm{~min}$, washed three times with distilled saline solution and inoculated into $100 \mathrm{~mL}$ MSM medium in $250 \mathrm{~mL}$ Erlenmeyer flasks amended with $0.1 \%(\mathrm{w} / \mathrm{v})$ heavy crude oil. The culture conditions were kept at $30{ }^{\circ} \mathrm{C}$ with shaking at $180 \mathrm{rpm}$ for 14 days. Meanwhile, a control group was established without adding strain C-1. All experiments were performed in triplicate.

The residual extra-heavy oil in each Erlenmeyer flask were extracted with $40 \mathrm{~mL} \mathrm{CCl}_{4}$ at time intervals of 1, 2, 4, 6, 8, 10, 12 and 14 days, and the extracted extra-heavy oil concentration was measured by an infrared (IR) spectrophotometer (OIL-460, China Invent Instrument Tech. Ltd., China) according to the national standard method in China. ${ }^{20}$ Meanwhile, the value of $\mathrm{OD}_{600}$ was measured for evaluating the influence of extra-heavy oil on the growth of strain C-1.

\subsection{Analysis of saturates, aromatics, resins, and asphaltenics in extra-heavy oil}

The relative content of saturates, aromatics, resins, and asphaltenics in extra-heavy oil were analyzed using the methods described. ${ }^{21}$ The oil was dissolved in $n$-heptane to separate insoluble asphaltenes, and further fractionated using activated alumina column chromatography. The aliphatic fractions were eluted with petroleum ether, the aromatic fractions were eluted with benzene, and after that, resin fractions were eluted with the mixture of dichloromethane and ethanol (1:1 volume ratio), dichloromethane and ethanol. The content of each fraction is obtained by weighing.

\subsection{GC-MS analysis of hydrocarbon degradation in extra-} heavy oil

The aliphatic and aromatic eluent were concentrated to a volume of $1.0 \mathrm{~mL}$, and then analyzed by GC-MS (Agilent 7890A/5975C, Agilent Technologies Inc., Santa Clara, CA, USA) equipped with an HP-5MS fused-silica capillary column. ${ }^{22}$ Peak areas of each compound were normalized with respect to the 
internal standard $(17(\alpha), 28(\beta)$-hopane) for $n$-alkanes and reported in this paper as relative abundance, using the methods described..$^{23,24}$

\section{Results and discussion}

\subsection{Isolation and identification of strain C-1}

Nine extra-heavy oil bacterial strains were isolated from longterm Venezuelan extra-heavy oil contaminated soil collected from the Liaohe oilfield. The strain that showed the highest degrading ability and grew best in extra-heavy oil, named C-1, was selected for further study. Strain C-1 is Gram-positive (Fig. 1b), rod-like and almost $1.29 \mu \mathrm{m}$ long (Fig. 1c). Colonies grown on $\mathrm{R}_{2} \mathrm{~A}$ agar for 3 days at $30{ }^{\circ} \mathrm{C}$ were smooth, circular convex, wet and orange in color (Fig. 1a).

The strain was first identified by classical biochemical tests, and then molecular identification was performed for strain C-1 by amplification and sequencing the $16 \mathrm{~S}$ rDNA sequencing and comparing them to the database of known 16S rDNA sequences. The results of biochemical identification were shown in Table 1. Strain C-1 was positive for catalase and negative for acid from glucose, oxidase, methyl red, nitrate reduction, indole production, citrate utilization, Voges-Proskauer reaction, hydrogen sulfide. The molecular identification of strain C-1 show that this strain belongs to Dietzia cercidiphylli (99\%). The phylogeny tree of this bacterium is shown in Fig. 2.

\subsection{Carbon source utilization of strain C-1}

Twelve kinds of carbon source were tested as sole carbon substrates of C-1, including various low and high molecular weights of PAHs and some kinds of $n$-alkanes. All of them exist ubiquitously in the oil contaminated soil. Strain C-1 was found to grow obviously with C16 $n$-alkanes and ethanol, while it grew a bit slower with C40 $n$-alkanes, but could not use cyclo-hexane (C6), C24 n-alkanes, naphthalene, phenanthrene, fluoranthene, anthracene, pyrene, benzene for growth (Table 2). It could be inferred that strain C-1 could degrade length and longer length chain $n$-alkanes of extra-heavy oil.

\subsection{Degradation kinetics of extra-heavy oil}

Remediation time can be roughly determined from the degradation step of hydrocarbons in the contaminated soil samples. A

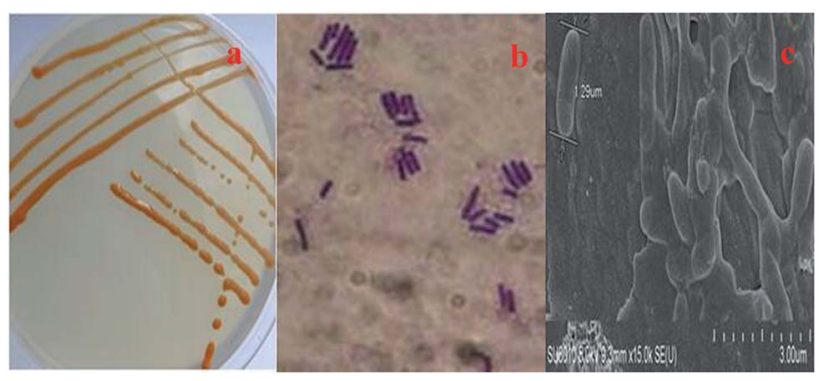

Fig. 1 Photographs of colonies and cells of strain C-1: (a) photograph of $\mathrm{C}-1$ colonies on $\mathrm{R}_{2} \mathrm{~A}$ solid media plate; (b) Gram stain photograph of $\mathrm{C}-1$; (c) SEM photograph of C-1 $(15.0 \times k)$.
Table 1 Typical biochemical characteristics of strain C-1

\begin{tabular}{ll}
\hline Characteristic & Strain C-1
\end{tabular}

Acid from glucose

Oxidase test

Catalase activity

Methyl red

Nitrate reduction

Indole production

Citrate utilization test

Voges-Proskauer

reaction

Hydrogen sulfide test

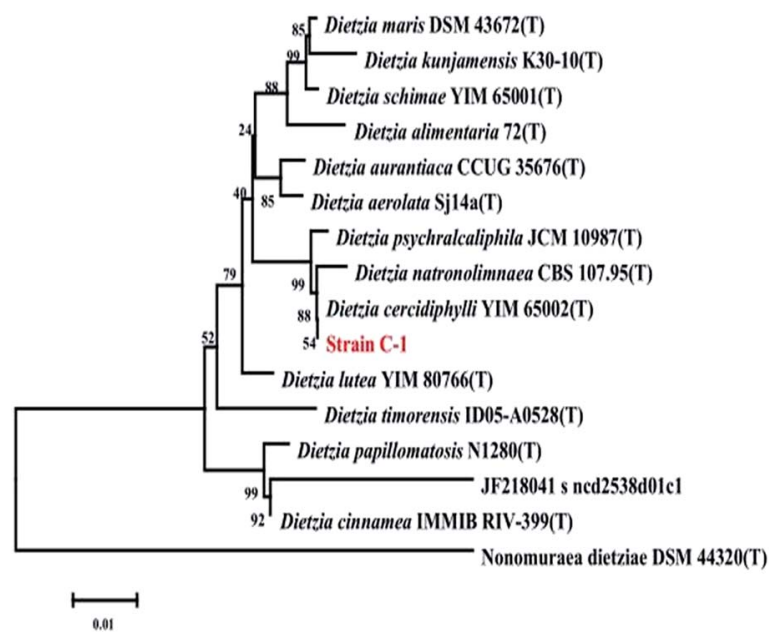

Fig. 2 Phylogenetic analysis of strain C-1 and related species by the Neighbor-Joining method based on 16S rDNA sequences. Bootstrap values (\%) are indicated at the nodes, the scale bars represent 0.01 substitutions per site.

number of experimental studies have shown that biodegradation kinetics can be approximated with first order kinetics: ${ }^{25-28}$

$$
y=C_{0} \mathrm{e}^{-k t}
$$

where $C$ is the residual oil content in the media at time $t$ (mg $\left.\mathrm{L}^{-1}\right), C_{0}$ is the initial oil content in the media $\left(\mathrm{mg} \mathrm{L}^{-1}\right), k$ is the biodegradation rate constant (per day) and $t$ is the time (day).

Change in the concentration of extra-heavy oil was shown in Fig. 3. During the initial 10 days, a decrease of concentration was observed, however, there was a gradual plateau from 10 to 14 days. Extra-heavy oil degradation kinetics was estimated in a first-order degradation rate model (Fig. 3), which gave good description of extra-heavy oil concentration changes. The firstorder rate coefficient $k$ (per day) was calculated by applying non-linear regression to the experimental data using SPSS. The $k$ value for extra-heavy oil degradation by strain C-1 was equal to 0.021 per day. Compared with other degradation rate coefficient, ${ }^{29,30}$ the $k$ value was higher. It indicated that strain C-1 had a good activity for degrading extra-heavy oil. 
Table 2 Utilization of carbon substrates by strain C-1 ${ }^{a}$

Carbon source

\section{n-C6}

Cyclohexane

n-C16

$n-\mathrm{C} 24$

$n-\mathrm{C} 40$

Naphthalene

Phenanthrene

Fluoranthene

Anthracene

Pyrene

Benzene

Ethanol

${ }^{a}$ Growth was followed by measuring the increase of $\mathrm{OD}_{600 \mathrm{~nm}}$ for 7 days. $(++)$ Good growth: $\mathrm{OD}_{600 \mathrm{~nm}}>0.2 ;(+)$ growth: $\mathrm{OD}_{600 \mathrm{~nm}}>0.1 ;(-)$ growth: $\mathrm{OD}_{600 \mathrm{~nm}}<0.05$.

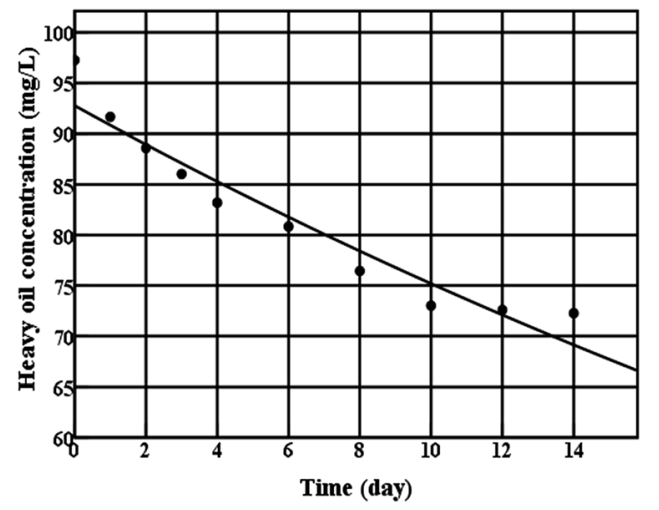

Fig. 3 Extra-heavy oil degradation kinetics curve of strain C-1 experimental data; - Monod model kinetic curve).

\subsection{Biodegradation of extra-heavy oil}

Cell growth and extra-heavy oil degradation efficiency of strain C-1 was presented in Fig. 4a. During the initial 10 days, rapid cell growth and sharp increase of extra-heavy oil degradation efficiency were monitored, after that, with the decrease of cell number, extra-heavy oil degradation efficiency remained the $25.58 \pm 0.48 \%$ (the largest degradation efficiency) until the end of the experiment (14 days). It showed that strain C-1 completely its degradation process of extra-heavy oil within 10 days. Comparisons with other heavy oil-degrading strains suggested that strain C-1 showed high activity in extra-heavy oil degradation. ${ }^{17,31}$ The result was consistent with the degradation kinetics of strain C-1.

Fig. $4 \mathrm{~b}$ showed the change of saturates, aromatics, resins, and asphaltenics in extra-heavy oil. After 14 days of incubation (on day 14), the relative content of aliphatics was decreased to $28.62 \%$ from $33.95 \%$, causing relative enrichment in aromatics, resins and asphaltenes and redistribution of relative content. It could be inferred that strain C-1 could only degrade aliphatics, but not aromatics, resins and asphaltenes in extra-heavy oil. To further verify the results, the variation of aliphatics and
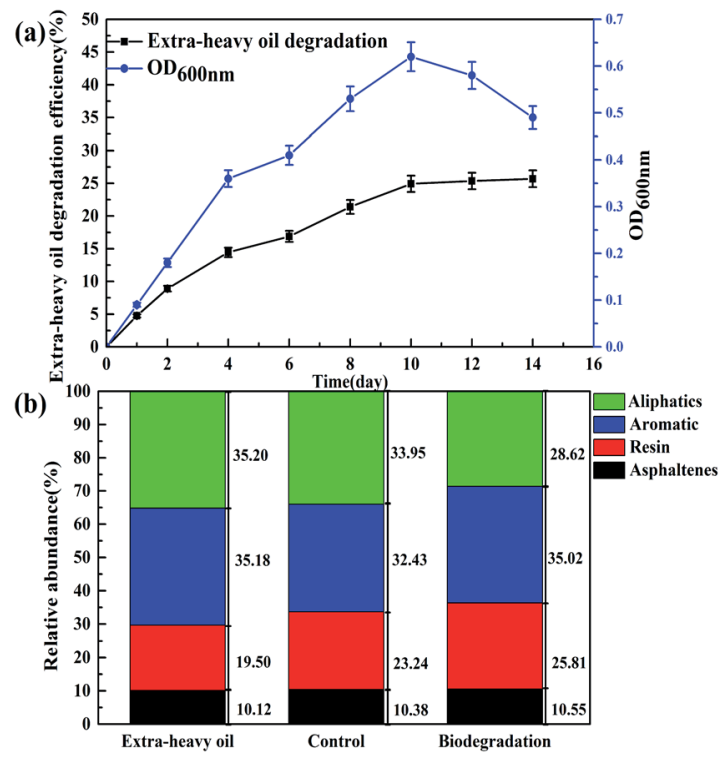

Fig. 4 Changes in degradation efficiency, microbial cell number (a) and four fractions (b).

aromatics was analyzed by GC-MS. GC-MS analysis demonstrated that strain C-1 could reduced aliphatics when compared to the control whereas no change of aromatics was monitored for strain C-1 (Fig. S2 $\dagger$ ).

The above results about the degradation characteristics of strain C-1 were consistent with previous studies. Although some Dietzia strains have been reported to utilize pure polycyclic aromatic groups for growth,,$^{17,31,32}$ no obvious degradation of polycyclic aromatic groups of crude oil had been reported for these strains. In addition, only the gene encoding alkanes terminal monooxygenases ${ }^{33}$ were amplified from Dietzia $\mathbf{s p . ; ^ { \mathbf { 1 6 , 1 7 } }}$ the gene encoding polycyclic aromatic groups dioxygenases ${ }^{34}$ has not yet been reported from Dietzia sp. More research is needed to answer this question (Fig. 5).

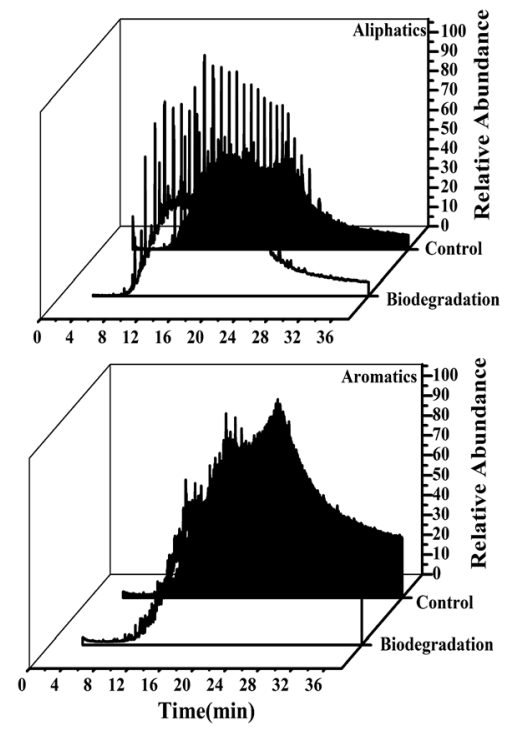

Fig. 5 GC-MS spectrum of aliphatics and aromatics of extra-heavy oil. 


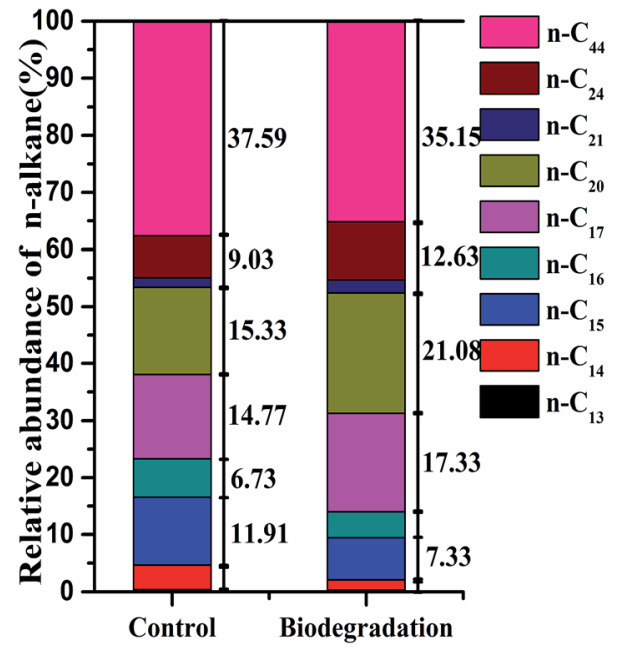

Fig. 6 Relative abundance (\%) of $n$-alkanes after 14 days of strain C-1 biodegradation.

\subsection{Biodegradation of $\boldsymbol{n}$-alkanes of extra-heavy oil}

Extra-heavy oil is a complex mixture primarily composed of insoluble compounds, including different chain-length $n$ alkanes, which are not easily dispersed in water. GC-MS analysis detected someindividual $n$-alkanes, which included $37.59 \%$ of $n$-C44; $24.36 \%$ of $n$-C20, $n$-C21, and $n$-C24; and $38.06 \%$ of $n$-C13$\mathrm{C} 17$ (Fig. 7). For strain $\mathrm{C}-1, n-\mathrm{C} 13-\mathrm{C} 17$ had higher removal efficiencies, followed by $n$-C44, $n$-C20, $n$-C21, and $n$-C24 (Fig. 7a). Fig. 7b shows that the 14 day removal efficiencies of $n$ C13, $n$-C14, $n$-C15, $n$-C16, $n$-C17, and $n$-C44 were $43.11 \pm 0.7 \%$, $69.43 \pm 1.3 \%, 55.69 \pm 0.8 \%, 51.49 \pm 0.4,15.56 \pm 0.3$ and $32.4 \pm$ $3.0 \%$, respectively; however, $n$-C20, $n$-C21, and $n$-C24 had almost no degradation. Variation in removal efficiencies led to changes in the relative abundance of $n$-C44, $n$-C20, $n$-C21, $n$-C24 and $n$-C1-C17 groups after 14 days of incubation (Fig. 6).
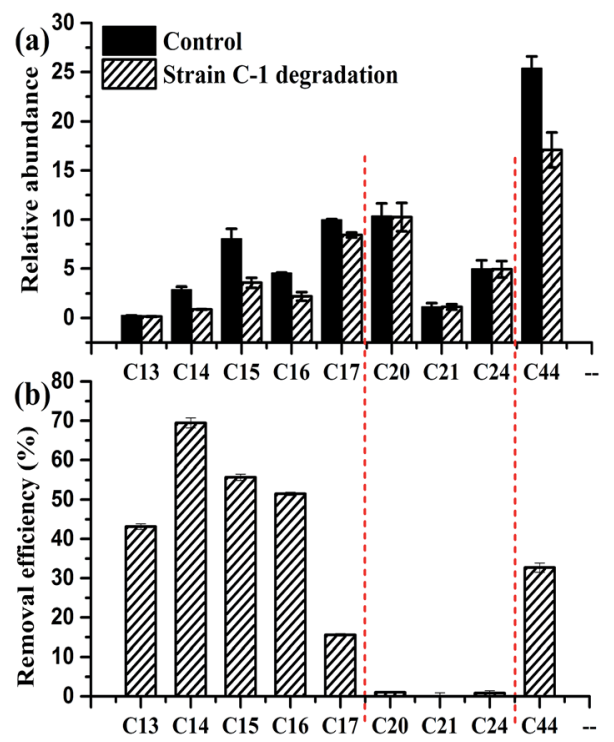

Fig. 7 Relative abundance (a) corresponding removal efficiencies (b) of individual $n$-alkanes compounds after 14 days of strain C-1 degradation.
The above results showed that strain $\mathrm{C}-1$ had better degradation for $n$-alkanes with medium length (C13-C17) chain and longer length (C44) chain, the n-alkanes with long length (including C20, C21 and C24) chain had no degradation. These findings are consistent with previous research. The widely accepted $n$-alkanes sequential degradation theory suggests that C12-C15 are preferentially degraded during the early stages of crude oil biodegradation, ${ }^{\mathbf{1 5 , 1 7}}$ which could be one of the reasons why strain C-1 had superiority in biodegradation C13-C17 hydrocarbons during the 14 days cultivation (Fig. 7). In fact, a novel AlkB rubredoxin fused alkane hydroxylase encoding gene was cloned in Dietzia strain DQ12-45-1b (strain C-1 belonging to Dietzia sp.) in an accompanying study with the GenBank Accession Number of HQ850582, which was proved to be responsible for the degradation of longer hydrocarbons. The CYP153 gene was cloned and sequenced in another accompanying study with the ability to degrade $n$-alkanes with the chainlength of C14 and C16. ${ }^{17}$ Overall, the chemical composition data (measured by GC-MS) corroborated the extra-heavy oil degradation data and carbon source utilization result, showing that strain C-1 could use length (C13-C17) and longer length chain (C44) n-alkanes as the sole carbon sources.

\section{Conclusions}

Strain C-1 belonging to the genus of Dietzia was isolated and characterized according to its biochemical characteristics and 16S rDNA sequences. It was Gram-positive, rod-like and almost $1.29 \mu \mathrm{m}$ long. Colonies were smooth, circular convex, wet and orange in color. It was positive for catalase and negative for acid from glucose, oxidase, methyl red, nitrate reduction, indole production, citrate utilization, Voges-Proskauer reaction, and hydrogen sulfide. Strain C-1 can utilize C16 n-alkanes, C40 nalkanes and ethanol as sole carbon source. Strain C-1 had a high extra-heavy oil degradation activity, and the reaction rate constant $k$ was 0.021 per day. In 14 days of degradation, the strain could degrade nearly $25.58 \pm 0.48 \%$ of extra-heavy oil. Four fractions and GC-MS analysis showed that strain C-1 could degrade aliphatics. GC-MS analysis also showed that strain C-1 could effectively degrade medium length (C13-C17) chain and longer length (C44) chain $n$-alkanes, but did not show obvious degradation for the long length (including C20, C21 and C24) chain $n$-alkanes. To date, it is first report that Dietzia strain is able to degrade extra-heavy oil, especially to C44 $n$-alkanes.

\section{Acknowledgements}

This work was funded by the National Natural Science Foundation of China (U1462201), and China National Petroleum Corporation projects (2014D-4607). We thank the Liaohe Petrochemical Company (Liaoning, China) for providing heavy oil samples.

\section{References}

1 R. Meyer and E. Attanasi, Geological Survey Fact Sheet 70-03, 2003, http://pubs.usgs.gov/fs/fs070-03/fs070-03.html. 
2 G. D. Ji, Y. S. Yang, Q. Zhou, T. Sunc and J. R. Ni, Environ. Int., 2004, 30, 509-517.

3 R. M. Palou, M. Lourdes Mosqueira, B. Z. Rendónb, E. M. Juárezc, C. B. Huicochead, J. C. C. Lópeze and J. Aburto, J. Pet. Sci. Eng., 2011, 75, 274-282.

4 H. J. Kang, S. Y. Lee, J. Y. Roh, U. H. Yim, W. J. Shim and J. H. Kwon, Environ. Sci. Technol., 2014, 48, 2962-2970.

5 M. Chen, P. Xu, G. M. Zeng, C. P. Yang, D. L. Huang and J. C. Zhang, Biotechnol. Adv., 2015, 33, 745-755.

6 A. Mrozik and Z. Piotrowska-Seget, Microbiol. Res., 2010, 165, 363-375.

7 H. Zhong, Y. Liu, Z. F. Liu, Y. B. Jiang, F. Tan, G. M. Zeng, X. Z. Yuan, M. Yan, Q. Y. Niu and Y. S. Liang, Int. Biodeterior. Biodegrad., 2014, 94, 152-159.

8 Y. Cheng, H. J. He, C. P. Yang, G. M. Zeng, X. Li, H. Chen and G. L. Yu, Biotechnol. Adv., 2016, 34, 1091-1102.

9 G. H. Lan, Q. Fan, Y. Q. Liu, Y. Liu, Y. C. Liu, X. B. Yin and M. N. Luo, Biochem. Eng. J., 2015, 103, 219-226.

10 L. Huang, T. Ma, D. Li, F. L. Liang, R. L. Liu and G. Q. Li, Mar. Pollut. Bull., 2008, 56, 1714-1718.

11 J. Vila and M. Grifoll, Appl. Environ. Microbiol., 2016, 82, 6232-6239.

12 Y. C. Liu, L. Z. Li, Y. Wu, W. Tian, L. P. Zhang, L. Xu, Q. R. Shen and B. Shen, Bioresour. Technol., 2010, 101, 310-316.

13 Z. Z. Zhang, L. X. Gai, Z. W. Hou, C. Y. Yang, C. Q. Ma, Z. G. Wang, B. P. Sun, X. F. He, H. Z. Tang and P. Xu, Bioresour. Technol., 2010, 101, 8452-8456.

14 H. J. Liu, J. Yao, Z. M. Yuan, Y. F. Shang, H. L. Chen, F. Wang, K. Masakorala, C. Yu, M. M. Cai, R. E. Blake and M. M. Choi, Int. Biodeterior. Biodegrad., 2014, 87, 52-59.

15 G. Bødtker, I. V. Hvidsten, T. Barth and T. Torsvik, Antonie van Leeuwenhoek, 2009, 96, 459-469.

16 Z. Bihari, Z. Szabó, A. Szvetnik, M. Balázs, P. Bartos, P. Tolmacsov, Z. Zombori and I. Kiss, Z. Naturforsch., C: J. Biosci., 2010, 65, 693-700.

17 X. B. Wang, C. Q. Chi, Y. Nie, Y. Q. Tang, Y. Tan, G. Wu and X. L. Wu, Bioresour. Technol., 2011, 102, 7755-7761.
18 D. J. Reasoner and E. E. Geldreih, Appl. Environ. Microbiol., 1985, 49, 1-7.

19 S. G. Holt, N. R. Kriey, P. H. A. Sneath, J. T. Staley and S. T. Williams, Bergy's manual of determinative for bacteriology, Williams and Wilkins, New York, 1998.

20 MEPChina, Chinese Ministry of Environmental Protection, 2012.

21 N. X. Huang, H. R. Ma, X. R. Wang, J. F. Feng and P. Ding, Journal of shanxi university of science \& technology (Shanxi Keji Daxue), 2003, 21, 25-29.

22 B. Cai, J. Ma, G. X. Yan, X. L. Dai, M. Li and S. H. Guo, Biochem. Eng. J., 2016, 112, 170-177.

23 R. C. Prlnce, D. L. Elmendorf, J. R. Lute, C. S. Hsu, C. E. Haith, J. D. Senius, G. J. Dechert, G. S. Douglas and E. L. Butler, Environ. Sci. Technol., 1994, 28, 142-145.

24 I. Tolosa, S. D. Mora, M. R. Sheikholeslami, J. P. Villeneuve, J. Bartocci and C. Cattini, Mar. Pollut. Bull., 2004, 48, 44-60.

25 P. Hohener, C. Duwig, G. Pasteris, K. Kaufmann, N. Dakhel and H. Harms, J. Contam. Hydrol., 2003, 66, 93-115.

26 E. Collina, G. Bestetti, P. Di Gennaro, A. Franzetti, F. Franzetti, M. Lasagni and D. Pitea, Environ. Int., 2005, 167-171.

27 J. L. Chen, M. H. Wong, Y. S. Wong and N. F. Y. Tam, Mar. Pollut. Bull., 2008, 57, 695-702.

28 S. Maletić, B. Dalmacija, S. Rončević, J. Agbaba and O. Petrović, Water, Air, Soil Pollut., 2009, 202, 149-159.

29 E. Y. Hwang, W. Namkoong and J. S. Park, Compost Sci. Util., 2001, 9, 143-149.

30 B. E. Abbassi and W. D. Shquirat, Water, Air, Soil Pollut., 2008, 192, 221-226.

31 I. V. D. Weid, J. M. Marques, C. D. Cunha, R. K. Lippi, S. C. C. D. Santos, A. S. Rosado, U. Lins and L. Seldin, Syst. Appl. Microbiol., 2007, 30, 331-339.

32 H. A. Awadhi, R. H. D. Sulaiman, H. M. Mahmoud and S. S. Radwan, Appl. Microbiol. Biotechnol., 2007, 77, 183-186.

33 L. Li, X. Liu, W. Yang, F. Xu, W. Wang, L. Feng, M. Bartiam, L. Wang and Z. H. Rao, J. Mol. Biol., 2008, 376, 453-465.

34 J. S. Seo, Y. S. Keum and Q. X. Li, Int. J. Environ. Res. Public Health, 2009, 6, 278-309. 